\title{
An Evaluation of Potential Inappropriate Prescribing Among Older Persons in Nigeria
}

\author{
Sule A Saka ${ }^{1}$, Frasia Oosthuizen ${ }^{1} \&$ Manimbulu Nlooto ${ }^{1}$ \\ ${ }^{1}$ Discipline of Pharmaceutical Sciences, College of Health Sciences, University of KwaZulu-Natal, Durban 4000, \\ South Africa \\ Correspondence: Sule A Saka, Discipline of Pharmaceutical Sciences, College of Health Sciences, University of \\ KwaZulu-Natal, Westville Campus, Durban 4000, South Africa. Tel: 277-32-233-014. E-mail: \\ sulsak01@yahoo.com,sulsak03@gmail.com
}

Received: July 19, 2018 Accepted: August 24, 2018 Online Published: October 13, 2018

doi:10.5539/gjhs.v10n11p28

URL: https://doi.org/10.5539/gjhs.v10n11p28

\begin{abstract}
Potential Inappropriate prescribing (PIP), Drug-Drug interactions (DDI) and polypharmacy are major risk factors for adverse drug reactions among older persons. Although these factors in many cases co-exist in prescriptions to older persons, very few studies have evaluated the inter-relationship between these factors concomitantly. This study aimed to evaluate PIP and DDI and to determine the associations between PIP, DDI, and polypharmacy among Nigerian older persons. This study was a retrospective evaluation of medicine utilization among older persons at Olabisi Onabanjo University Teaching Hospital, Nigeria, using a medical chart review. Older persons aged $\geq 60$ years, with chronic diseases that attended the medical outpatient clinics of the hospital between $1^{\text {st }}$ January and $31^{\text {st }}$ December 2016 were included. Eligible patients' records were randomly sampled. Information including patients' demographics, medical and medication histories and current medications were extracted with a checklist. PIP and DDI were evaluated using the 2015 updated Beers Criteria. Associations were determined using Chi-squared test and a binary logistic regression. A total of 352 participants, mean age $69.03 \pm 7.35$ years were evaluated. According to the Beers Criteria, PIP and DDI among the participants were $(124 / 352,35.2 \%)$ and $(20 / 352,5.7 \%)$ respectively. Majority of the participants $(192 / 352,54.5 \%)$ received polypharmacy. A few participants (12/352. 3.4\%) received prescriptions containing PIP, DDI, and polypharmacy concomitantly. DDI was significantly associated with PIP in a logistic regression $(\mathrm{OR}=0.18,95 \% \mathrm{CI}=0.05-0.68, \mathrm{p}=0.01)$ and with polypharmacy in a Chi-squared test $(\mathrm{OR}=3.55,95 \% \mathrm{CI}=1.16-10.83, \mathrm{p}=0.02)$. This study concludes that PIP, DDI and polypharmacy are interrelated and should be considered when prescribing to older persons.
\end{abstract}

Keywords: amitriptyline, Beers Criteria, drug interaction, Nigeria, polypharmacy

\section{Introduction}

The triad of Potential Inappropriate Prescribing (PIP), polypharmacy and Drug-Drug Interactions (DDI) are responsible for many Adverse Drug Reactions (ADRs) among older persons worldwide (Van der Stelt et al., 2016; Davies \& O'Mahony, 2015; Obreli-Neto et al., 2012). The negative effects of ADRs on morbidity, mortality and healthcare costs among older persons are well established in the literature (Davies \& O'Mahony, 2015; Hamilton, Gallagher, Ryan, Bryne, \& O'Mahony, 2011). However, most studies on PIP among older persons have evaluated each factor separately using different tools and criteria, thus, making data comparison difficult.

Many explicit criteria have been developed in different countries to screen for PIP among older persons (American Geriatric Society [AGS], 2015; O’Mahoney et al., 2015; Renom-Guiteras, Meyer \& Thurmann, 2015; Holt, Schmiedl \& Thurman, 2010). The Beers Criteria and the Screening Tool of Older People's Prescriptions and Screening Tool to Alert to Right Treatment (STOPP/START Criteria) developed in America and Ireland respectively are among the most cited (O'Mahony et al., 2015). Previous studies that applied the Beers Criteria to screen for PIP among older persons in the developed world reported a wide range of prevalence ranging between $15 \%$ and $44 \%$ depending on the study population and the clinical setting (Novaes, da Cruz, Lucchetti, Leite \& Lucchetti, 2017; Narayan \& Nishtala, 2015; Elliot \& Stehlik, 2013). Similar prevalence has been reported among older persons in many low and middle-income countries (LMICs) including Africa (Rakesh, Chowta, Shenoy, Shastry \& Pai, 2017; van Heerden, Burger, \& Gerber, 2016; Fadare, Agboola, Opeke, \& Alabi, 2013; Eze \& Olowu, 2011). In many of these previous studies, medication including anticholinergics, sedatives and 
non-steroidal anti-inflammatory drugs (NSAIDs) were widely reported to be mostly inappropriately prescribed among the participants (van Heerden et al., 2016; Narayan \& Nishtala, 2015; Fadare et al., 2013). With a few exemptions (Rakesh et al., 2017; Fadare et al.,2013), almost all these studies used prescriptions from databases or from the hospital records which did not contain certain patients' clinical profiles, which are necessary for estimation of PIP due to kidney function and drug-disease interactions (van Heerden et al., 2016; Ubeda et al., 2012; Eze \& Olowu, 2011).

Few studies have also compared the STOPP/START criteria with the earlier versions of the Beers Criteria, with the STOPP Criteria being reported to be more sensitive to PIM than the Beers criteria (Bahat et al., 2017; Ubeda et al., 2012). The earlier versions of the Beers criteria have however been criticized for non-inclusion of common categories of PIP such as drug-drug, drug-disease interactions, drug duplication and the inclusion of obsolete medications (O'Mahony et al., 2015; Page, Linnebur, Bryant, \& Ruscin, 2010). However, with a major review that the Criteria have undergone since adoption by the American Geriatric Society (AGS) in 2012, most of the criticisms appeared to have been addressed (AGS, 2015).

Traditionally, DDI has been evaluated using web-based tools (Salwe, Kalyansundaram, \& Buhurupi, 2016; Shoshi, Hoppe, Kormeier, Ogultarhan, \& Hofestadt, 2015). However, the web-based instruments assess DDI that are non-specific to older persons alone and for which the risk of serious harms to older persons is uncertain (Salwe et al, 2016). Polypharmacy is often evaluated using the World Health Organization definition "the administration of many drugs at the same time or the administration of an excessive number of drugs" (World Health organization [WHO], Centre for Health Development, 2004).

In Nigeria, studies on PIP among older persons are scarce. However, two studies that utilized the earlier versions of the Beers Criteria reported a PIP prevalence of 30.3\% and 45.6\% among older Nigerians (Fadare et al., 2013; Eze \& Olowu, 2011). In these previous studies, associations between polypharmacy, PIP and DDI were not assessed. The co-existence of polypharmacy, DDI and PIP in many prescriptions to older persons is established in the literature (Novaes et al., 2017; Rakesh et al., 2017). However, very few studies have evaluated the associations of the triad concurrently. ${ }^{11}$ This study aimed to evaluate the prevalence of PIP and DDI using the 2015 updated AGS-Beers Criteria and to determine the associations between PIP, DDI, and polypharmacy among older Nigerians.

\section{Methods}

\subsection{Study Population, Inclusion and Exclusion Criteria}

This study was a cross-sectional retrospective evaluation of medicine utilization among older persons using a medical chart review. This study's inclusion criteria were participants being aged $\geq 60$ years with at least one chronic disease, attendance of the hospital's MOP clinics between $1^{\text {st }}$ January and $31^{\text {st }}$ December 2016 . The age $\geq 60$ years was used to define older persons in this study in line with United Nations cut-off, and this is consistent with previous studies in many LMICs (Rakesh et al., 2017; Eze \& Olowu, 2011). This study adopted the World Health Organization's (WHO) definition of chronic disease (WHO, 2002). Physician diagnosis recorded in the chart was relied on for the identification of chronic diseases. Participants were excluded if the demographics and medical information were incomplete [age, diagnosis, current medication, creatinine clearance (when necessary)], received no prescriptions, due to referral to another level of care or on clinic revisit. Eligible participants whose records were used in the pilot stage of the study were excluded.

\subsection{Study Setting}

The study was carried out at the medical outpatients (MOP) clinics of Olabisi Onabanjo University Teaching Hospital, Nigeria. The hospital is a 205-bed public tertiary healthcare facility and a referral center for many hospitals in the South-western region of the country. The hospital had no geriatric unit at the time of the study, but there were few geriatricians that consulted in the MOP clinics.

\subsection{Sample Size Estimation}

A total of 2,326 eligible participants were available for selection based on the inclusion criteria. The sample size was calculated using a $50 \%$ response distribution, a $5 \%$ margin of error at $95 \%$ confidence level yielding a minimum size of 330 . A $10 \%$ attrition rate was added to the minimum size to obtain a maximum sample size of 363 (Charan \& Biswas, 2013).

\subsection{Data Collection Technique}

Medical charts of eligible participants were selected from the hospital's medical records office with the aid of a trained research assistant. Patients identifiers were entered into Excel software and cleaned to remove double 
entries. Medical records of eligible participants were randomly selected until the sample size was complete. A researcher-designed checklist which had earlier been pre-tested using 10 randomly selected medical records of eligible participants in the facility was used for data capturing. The checklist captured participants' socio-demographics, social and clinical information including diagnosis, medical and medication histories, current medication and eGFR (or Creatinine clearance where available). The checklist also captured prescribers' cadres, MOP clinics, and the prescription date. The period was analyzed on a quarterly basis.

The prescriptions offered to the participants on first clinic visit only during the study period were evaluated. The prescriptions were evaluated for PIP and DDI using a full application of the 2015 updated AGS-Beers Criteria. Medical history and present diagnosis were assessed together for the determination of PIMs to be avoided in certain diseases and syndromes. Where a PIP due to kidney function was suspected from the prescription of a medicine listed in the category by the Beers Criteria, the patient's creatinine clearance was assessed. The creatinine clearance obtained not later than 6 months before the study was considered valid. The two commonly applied definitions of polypharmacy were adopted and evaluated in this study. Five or more medicines in a prescription were regarded as polypharmacy (category A) (Rakesh et al., 2017). Prescription of medicines more than clinically indicated was considered as polypharmacy (category B) (WHO, 2004). The category B consists of prescriptions containing drug class duplication or combinations of medicines with the same active ingredients in a way that the daily dose of any of the active ingredients exceeded the standard dose. The defined daily dose by the WHO was used for the standard dose determination. ${ }^{24}$ The prescriptions were also assessed for conformity with the Nigerian Standard Treatment Guidelines (NSTG) (Federal Ministry of Health [FMOH], 2008). Diseases were categorized using the International Classification of Diseases (ICD-10 version 2016). PIM was classified using Anatomical Therapeutic Chemical Classification (ATC) system (Collaborating Centre for Drug Statistics Methodology, 2010). A clinical pharmacist reviewed the medical charts.

\subsection{Data Management and Analysis}

The data were captured into Excel worksheet from the checklist by a graduate research assistant and were cleaned manually. The entry was double checked for errors by the second author. The data were fed into the Statistical Packages for the Social Sciences (version 25) and were primarily analyzed within a quantitative framework using descriptive statistics. Student independent T-test was used to compare means of normally distributed continuous variables. A binary logistic regression was used to determine associated risk factors for PIP among the participants. In the final model independent variables including age, gender, number of chronic diseases, exposure to NSAIDs and antidepressants, polypharmacy were assessed. Variables with $\mathrm{p}<0.05$ in the univariate analysis were retained. However, exposure to PIM was forced into the model. The results were presented using odds ratio with $95 \%$ confidence interval. The Hosmer-Lemeshow goodness of fit was used to assess the adequacy of the final models. P $<0.05$ was considered significant.

\subsection{Ethical Approval}

This study was approved by the Biomedical Research Ethics Committee (BREC) of University of KwaZulu-Natal under reference number BE 591/16 and Olabisi Onabanjo University Teaching Hospital Ethical Review Committees under reference number OOUTH/HREC/97/2016. Gate-keeper permission was obtained from the head of the MOP department in the facility.

\section{Results}

\subsection{The Baseline Characteristics of the Study Participants}

Table 1 presents the baseline characteristics of the study participants based on gender distribution. Out of the 363 participants' records selected, only $(352 / 363,97.0 \%)$ were eventually analyzed. The remaining 11/352 (3.0\%) were found unusable because of missing records. The 352 participants had a mean age of $69.03 \pm 7.35$ years (95\%CI 68.26-69.80, Range $=60-91$ years). The study participants received treatments in 13 different clinics of the MOP. Almost half of the participants $(164 / 352,46.6 \%)$ received prescriptions in the cardiology unit, followed by Neurology clinic $(70 / 352,19.9 \%)$. Almost one-third of the participants $(111 / 352,31.5 \%)$ attended the hospital during the last quarter of the year. The period of medicine prescribing was not significantly associated with PIP $(\mathrm{p}=0.24)$. 
Table 1 . The baseline characteristics of the study participants

\begin{tabular}{|c|c|c|c|c|}
\hline Variables & Group & $\begin{array}{l}\text { Female }(\mathrm{n}=203) \\
\mathrm{n}(\%)\end{array}$ & $\begin{array}{l}\text { Male }(n=149) \\
n(\%)\end{array}$ & p-value \\
\hline Mean age (mean $\pm \mathrm{SD}, 95 \% \mathrm{CI}$ ) & $69.03 \pm 7.35$ years $(68.26-69.80)$ & $70.03 \pm 7.65$ years & $68.29 \pm 7.04$ years & 0.26 \\
\hline \multirow{4}{*}{ Age } & $60-69$ years $(n=208)$ & $134(38.1)$ & $74(21.0)$ & \multirow{4}{*}{0.006} \\
\hline & $70-79$ years $(n=102)$ & $52(14.8)$ & $50(14.2)$ & \\
\hline & $80-89$ years $(n=40)$ & $16(4.5)$ & $24(6.8)$ & \\
\hline & 90 years and above $(n=2)$ & $1(0.3)$ & $1(0.3)$ & \\
\hline \multirow{2}{*}{ Marital status } & Single & $114(32.4)$ & $23(6.5)$ & \multirow{2}{*}{$<0.001$} \\
\hline & Married & $89(25.3)$ & $126(35.8)$ & \\
\hline \multirow{4}{*}{ Highest educational qualification } & No formal education $(\mathrm{n}=129)$ & $96(27.3)$ & $33(9.4)$ & \multirow{4}{*}{$<0.001$} \\
\hline & $\operatorname{Primary}(\mathrm{n}=82)$ & $44(12.5)$ & $38(10.8)$ & \\
\hline & $\operatorname{Secondary}(\mathrm{n}=65)$ & $24(6.8)$ & $41(11.6)$ & \\
\hline & Post-secondary $(\mathrm{n}=76)$ & $39(11.1)$ & $37(10.5)$ & \\
\hline \multirow{4}{*}{ Occupation } & Public $(\mathrm{n}=19)$ & $12(3.4)$ & $7(2.0)$ & \multirow{4}{*}{0.004} \\
\hline & Private $(n=9)$ & $0(0.0)$ & $9(2.6)$ & \\
\hline & Self-employed (184) & $82(23.3)$ & $58(16.5)$ & \\
\hline & Retired $(n=140)$ & $109(31.0)$ & $75(21.3)$ & \\
\hline Mean number of chronic disease & $1.39 \pm 0.54(1.33-1.45)$ & $1.41 \pm 0.55$ & $1.36 \pm 0.53(-0.06-0.17)$ & 0.32 \\
\hline \multirow{3}{*}{ Number of chronic diseases } & One $(n=224)$ & $124(35.2)$ & $100(28.4)$ & \multirow{3}{*}{0.41} \\
\hline & Two $(n=120)$ & $75(21.3)$ & $45(12.8)$ & \\
\hline & $\geq$ Three $(\mathrm{n}=8)$ & $4(1.1)$ & $4(1.1)$ & \\
\hline \multirow{7}{*}{ ICD classification of diseases } & Circulatory system $(n=205)$ & $109(31.0)$ & $96(27.3)$ & \multirow{7}{*}{0.085} \\
\hline & Musculoskeletal system $(n=39)$ & $24(6.8)$ & $15(4.3)$ & \\
\hline & Nervous system $(n=22)$ & $15(4.3)$ & $7(2.0)$ & \\
\hline & Genitourinary $(n=19)$ & $15(4.3)$ & $4(1.1)$ & \\
\hline & Digestive system $(n=14)$ & $5(1.4)$ & $9(2.6)$ & \\
\hline & Infectious diseases $(n=11)$ & $7(2.0)$ & $4(1.1)$ & \\
\hline & Others* $(n=42)$ & $28(8.0)$ & $14(4.0)$ & \\
\hline
\end{tabular}

*Chi-squared value significant at $\mathrm{p}<0.05$. others include diseases of endocrine system, neoplasm, ear, blood forming organs, respiratory, eye and diseases involving more than 1 system.

\subsection{Prevalence of Potential Inappropriate Prescribing According to Diseases}

Table 2 presents the distribution of PIM according to the disease conditions. The study participants (124/352, $35.2 \%)$ received at least one PIM independent of diagnosis according to the AGS-Beers Criteria. Majority of the participants with musculoskeletal system disorders $(29 / 39,74.4 \%)$ and nervous system disorders $(15 / 22,68.2 \%)$ received PIM during the study period. 
Table 2. The distribution of PIM among the study participants according to diseases

\begin{tabular}{lll}
\hline Classification of diseases & No PIM & PIM \\
& $\mathrm{n}(\%)$ & $54(26.3)$ \\
\hline Diseases of circulatory system $(\mathrm{n}=205)$ & $151(73.7)$ & $29(74.4)$ \\
Diseases of musculoskeletal system(n=39) & $10(25.6)$ & $15(68.2)$ \\
Diseases of Nervous system $(\mathrm{n}=22)$ & $7(31.8)$ & $5(26.3)$ \\
Diseases of genitourinary system $(\mathrm{n}=19)$ & $14(73.7)$ & $3(21.4)$ \\
Diseases of digestive system $(\mathrm{n}=14)$ & $11(78.6)$ & $3(27.3)$ \\
Infectious and parasitic diseases(n=11) & $8(72.7)$ & $15(35.7)$ \\
Others* $(\mathrm{n}=42)$ & $27(64.3)$ & $124(35.2)$ \\
Total & $228(64.8)$ & .
\end{tabular}

*others include diseases of endocrine system, neoplasm, ear, blood forming organs, respiratory, eye and diseases involving more than 1 system.

\subsection{The Utilization of PIM Among the Study Population}

Table 3 presents the PIM utilization among the participants according to ATC classification. A total of 239 medicines were prescribed in 1845 encounters. Almost one-fifth of the medicine encounters $(352 / 1845,19.1 \%)$ resulted in PIM use, involving 23 medicines. Among the participants that received PIM (124/352, 35.2\%) antidepressants $(36 / 124,29.0 \%)$ and NSAIDs with combinations $(29 / 124,23.4 \%)$ were the most commonly prescribed PIM among the participants (Appendix 1).

Table 3. The PIM among the participants according to ATC classification

\begin{tabular}{lll}
\hline Class of medications & Frequency & Percentages \\
\hline Antidepressants (N06A) & 36 & 29.0 \\
Psychoanaleptics (N06CA01) & 5 & 4.0 \\
Psycholeptics (N05) & 11 & 8.9 \\
NSAIDs, in combination (M01A) & 29 & 23.4 \\
Cardiac drugs (C01) & 4 & 3.2 \\
Antihypertensives (C02) & 13 & 10.5 \\
Antihistamine preparations (R06A) & 4 & 3.2 \\
Antiemetics (A04A) & 1 & 0.8 \\
Opioids (N02A) & 5 & 4.0 \\
Antidiabetics (A10B) & 1 & 0.8 \\
Antiparkinson drugs (N04) & 13 & 10.5 \\
Antiepileptic drugs (N03) & 2 & 1.6 \\
& 124 & 100.0 \\
\hline
\end{tabular}

\subsection{Prevalence of Polypharmacy}

An average of $4.60 \pm 1.65$ medicines was prescribed per prescription (range 1-12). Majority of the participants $(192 / 352,54.5 \%)$ received polypharmacy (category A), of which 2 out 192 were hyper-polypharmacy cases $(\geq 10$ medicines prescribed). A few cases of polypharmacy (category B) was encountered (7/352, 2.0\%). Paracetamol was duplicated in prescriptions $(5 / 7,71.4 \%$ ) containing coproxamol (dextropropoxyphene+ paracetamol) and amitriptyline. Paracetamol was also duplicated in $(1 / 7,14.3 \%)$ prescription containing Coproxamol $^{\circledR}$ and Celecoxib $^{\circledR}$. Diclofenac was duplicated in $(1 / 7,14.3 \%)$ prescription containing diclofenac + Arthrotec ${ }^{\circledR}$ (diclofenac/misoprostol) and Cocodamol $^{\circledR}$ (codeine+ paracetamol). 
Table 4 presents the medicines with potential DDI prescribed to the study participants. A few of the prescriptions (20/352, 5.7\%) contained PIP due to potential DDI (see Appendix 2). A total of (12/352, 3.4\%) prescriptions contained PIP, DDI according to the AGS-Beers Criteria, and polypharmacy (category A) concurrently. A Chi-squared test showed a significant association between DDI and polypharmacy among the participants $(\mathrm{OR}=3.55,95 \% \mathrm{CI}=1.16-10.83, \mathrm{p}=0.02)$

Table 4. The DDI among study participants

\begin{tabular}{lll}
\hline Drug-drug interactions & Frequency & Percentage (\%) \\
\hline 2 anticholinergic combinations & 8 & 40.0 \\
3 Central Nervous drugs combinations & 1 & 5.0 \\
Angiotensin Enzyme Inhibitors +Amiloride combinations & 8 & 40.0 \\
Corticosteroids + Non-steroidal anti-inflammatory drugs & 2 & 10.0 \\
Alpha blocker +loop diuretic & 1 & 5.0 \\
\hline
\end{tabular}

\subsection{Drug-Disease Interactions}

Only $(2 / 352,0.6 \%)$ prescriptions contained PIP due to drug-disease interactions. This included amitriptyline for a participant with a history of falls and diclofenac for a participant with heart failure. Spironolactone was prescribed for $(1 / 352,0.3 \%)$ participant with end-stage renal failure $(\mathrm{Cr} / \mathrm{cl}<30 \mathrm{ml} / \mathrm{min})$. Only $(7 / 352,2.0 \%)$ of the prescriptions deviated from the NSTG.

\subsection{Associations Between Variables and Potential Inappropriate Prescribing Using Bivariate Logistic Regression}

Table 5 presents associations of variables with PIP. Chi-square test revealed no association between prescribers' status and $\mathrm{PIP}(\mathrm{OR}=0.79,95 \% \mathrm{CI}=0.42-1.50, \mathrm{p}=0.47)$. There was a significant association between antidepressants and $\mathrm{PIP}(\mathrm{OR}=0.02,95 \% \mathrm{CI}=0.004-0.08, \mathrm{p}<0.001)$ in the regression analysis.

Table 5. The risk factors associated with PIP in a binary logistic regression

\begin{tabular}{llll}
\hline Variable & $\mathrm{n}(\%)$ & OR $(95 \% \mathrm{CI})$ & P-value \\
\hline Age $($ Mean $\pm \mathrm{SD})$ & $69.46 \pm 7.09$ years & $1.04(0.98-1.09)$ & 0.21 \\
Gender (male) $\mathrm{n}=149$ & $47(31.5)$ & $1.32(0.73-2.38)$ & 0.35 \\
Number of chronic diseases (Mean $\pm \mathrm{SD})$ & $1.52 \pm 0.61$ & $1.53(0.48-4.80)$ & 0.46 \\
Musculoskeletal disorders $(\mathrm{n}=39)$ & $29(74.4)$ & $0.21(0.08-0.55)$ & $0.001^{*}$ \\
Nervous disorder $(\mathrm{n}=22)$ & $15(68.2)$ & $0.12(0.04-0.34)$ & $<0.001^{*}$ \\
Number of medications $(\mathrm{Mean} \pm \mathrm{SD})$ & $5.23 \pm 1.92$ & $0.94(0.62-1.42)$ & 0.76 \\
Polypharmacy (Category A) $(\mathrm{n}=124)$ & $79(63.7)$ & $0.97(0.37-2.58)$ & 0.96 \\
Antidepressants N06A $(\mathrm{n}=38)$ & $36(94.7)$ & $0.02(0.004-0.08)$ & $<0.001^{*}$ \\
NSAIDs in combination $\mathrm{M} 01 \mathrm{~A}(=32)$ & $29(90.6)$ & $0.08(0.02-0.28)$ & $<0.001^{*}$ \\
Drug-drug interactions $(\mathrm{n}=20)$ & $16(80.0)$ & $0.18(0.05-0.66)$ & $0.01^{*}$ \\
\hline
\end{tabular}

*significant $\mathrm{p}$-value $<0.05$. Hosmer-Lemeshow test for goodness of fit. $\mathrm{X}^{2}=3.85 \mathrm{df}=8 \mathrm{p}=0.87$.

\section{Discussion}

This study evaluated PIP and DDI using the 2015 AGS-Beers Criteria and determined the associations between the PIP, DDI, and polypharmacy among older persons with chronic diseases in Nigeria. In this study, only a few participants (3.4\%) received PIP and DDI according to the 2015 Beers Criteria, and polypharmacy concomitantly. This was lower compared with 29.3\% reported in Brazil (Novaes et al., 2017). This Brazilian study applied web-based tool to evaluate DDI. This could have over-estimated the prevalence of DDI, unlike this present study that used the 2015 Beers list which was specific for older persons.

More than one-third (35.2\%) of the participants received at least one PIM independently of diagnosis. The 
prevalence of PIP in this study was comparable to the findings of similar studies that utilized 2012 AGS-Beers Criteria in many parts of the globe (Bahat et al., 2017; Novaes et al., 2017; van der Stelt et al., 2016). This study finding was, however, lower compared with $45.6 \%$ reported in a previous study that applied the 2003 Beers Criteria in the same study site (Eze \& Olowu, 2011). This was probably because a few of the PIMs such as nifedipine (immediate release dosage) that were reported in the previous study were no longer in clinical use in the country at the time of the present study. A major criticism of the earlier Beers criteria was the inclusion of obsolete medications, which the 2015 updated Criteria appeared to have overcome. In addition, the previous study in the hospital evaluated PIP among a general population of older persons, unlike this study that focused on older persons with chronic diseases. The observation of the present study probably indicated more awareness and better practice among the attending physicians in the healthcare facility.

NSAIDs and antidepressants were the most prescribed class of PIMs in this study. This was consistent with the previous studies that utilized the 2012 Beers among older persons including Africans (van Heerden et al., 2016; Chang et al., 2015; Fadare et al., 2013). The high use of these medications could however be attributed to the prevalence of musculoskeletal system disorders and other neuropathy associated chronic diseases among the study participants. NSAIDs are regarded a PIM when used as first-line for pain or for a long period without a gastroprotective agent (AGS, 2015). It can increase the risks of gastrointestinal bleeding and cardiovascular accident among older persons (Park \& Bavry, 2014). The negative impacts of antidepressants including amitriptyline on older persons' quality of life are well documented. Apart from contributing to falls leading to fracture and accelerating gait decline, the anticholinergic effects are pronounced among older persons (de Jong, Elst, \& Hartholt, 2013). It was noted however that antidepressant specifically amitriptyline was mostly prescribed in this study for neuropathic pains, similar to the observation of a study in South-Africa (van Heerden et al., 2016). This appeared to be due to the relatively high cost of alternatives in these conditions and the recommendation of the NSTG (FMOH, 2008).

Based on the 2015 AGS-Beers Criteria only a few cases (5.7\%) of DDI was found in this study. This result was comparable to $(7.7 \%)$ reported in a similar study that used the same Criteria among Medicare beneficiaries in California, United States (Patel et al., 2018). The prevalence of DDI in this study contradicted the higher prevalence of DDI reported by many studies that utilized web-based DDI assessment tools (Novaes et al., 2017; Salwe et al., 2016; Obrieli-Neto et al., 2012). This was understandable considering the fact that the AGS-Beers Criteria DDI list targeted only DDI with strong evidence of causing harms among older persons (AGS, 2015).

Polypharmacy (Category A) was found among a slight majority (54.5\%) of the participants. Studies that applied the same definition of polypharmacy as this present study ( $\geq 5$ medicines per prescription) among older persons in LMICs reported similar findings (Novaes et al, 2017; Rakesh et al., 2017; Fadare et al., 2013). A few cases of polypharmacy (Category B) was observed in this study. These cases were due to prescription errors and the failure of the prescribers to comply with the recommendation on generic prescribing of medicines. Polypharmacy in older persons is associated with a greater risk of adverse drug reactions, drug interactions, higher health care expenditure, patients' non-adherence to medication, and reduced functionality among older persons (Maher, Hanlon, \& Hajjar, 2014).

This study identified musculoskeletal and nervous system disorders, antidepressants and NSAIDs as risk factors for PIP among the participants. To the best of authors' knowledge, this present study was the first to associate musculoskeletal disorders with PIP among African older persons. Studies reporting association between diseases and PIP in Africa were almost non-existent at the time of this study. Age, gender and numbers of medication and chronic diseases were not associated with PIP in this study, similar to previous studies among Indians, and Japanese older persons (Pradhan et al., 2015; Kondo et al., 2015).

Prescribers' status did not significantly influence PIP in this study. This indicated that PIP is an issue that requires educational interventions. This study observed a high adherence to the NSTG by the prescribers despite the level of PIP in the facility. Treatment guidelines are a fundamental basis on which medical practice is based (Davies \& O'Mahony, 2015). This study finding suggests that incorporation of the PIM alternatives into NSTG for the management of older persons' diseases may assist in reducing PIP among older persons.

\subsection{Limitations of the Study}

This study utilized data from a single center, a tertiary healthcare facility. The finding may, therefore, not be generalized. Physicians justification for using the PIM was not evaluated in this study. It was possible some of the PIMs might have clinical justifications among the participants. Majority of the prescriptions could also have emanated from physicians who were not trained in geriatrics because there were few geriatricians in the hospital at the time of the study. The results of this study should, therefore, be interpreted within the context of these 
limitations. A study on clinical and pharmacoeconomic benefits of stringent application of the updated 2015 Beers Criteria among older persons in Nigeria may be necessary.

\section{Conclusions}

This study identified a few prescriptions with PIP, DDI, and polypharmacy concurrently. The triad of PIP, DDI and polypharmacy were found to be inter-related. Amitriptyline (antidepressant) was responsible for many of the PIP, polypharmacy, and DDI in this study. Musculoskeletal and nervous disorders were associated with PIP among the study participants. Educational interventions to improve prescribing quality to older persons in Nigeria are advocated.

\section{Acknowledgements}

The authors are grateful to the Research Office, College of Health Sciences, UKZN and the staff and management of OOUTH. We also acknowledge Prof. Azu Onyemaechi for reviewing the manuscript and Prof Ben Sartorius for the guidance on the statistical analysis.

\section{Competing Interests Statement}

All the authors declare that there is no conflict of interests in the study.

\section{References}

American Geriatrics Society Beers Criteria Update Expert P. (2015). American Geriatrics Society 2015 Updated Beers Criteria for Potentially Inappropriate Medication Use in Older Adults. Journal of American Geriatric Society, 63(11), 2227-46. https://doi.org/10.1111/jgs.13702

Bahat, G., Bay, I., Tufan, A., Tufan, F., Kilic, C., Karan, M. A. (2017). Prevalence of potentially inappropriate prescribing among older adults: A comparison of the Beers 2012 and Screening Tool of Older Person's Prescriptions criteria version 2. Geriatrics \& Gerontology International, 17(9), $1245-51$. https://doi.org/10.1111/ggi.12850

Chang, C., Yang, S., Lai, H., Wu, R., Liu, H., Hsu, H......\& Chan, D. (2015). Application of three different sets of explicit criteria for assessing inappropriate prescribing in older patients: a nationwide prevalence study of ambulatory care visits in Taiwan. British Medical Journal Open, 5(11), e008214. https://doi.org/10.1136/bmjopen-2015-008214

Charan, J., \& Biswas, T. (2013). How to calculate sample size for different study designs in medical research. Indian Journal of Psychological Medicine, 35(2), 121-126. https://doi.org/10.4103/0253-7176.116232

Collaborating Centre for Drug Statistics Methodology. (2009). Guidelines for ATC classification and DDD assignment 2010. Oslo, 2009. Retrieved from http://www.whocc.no/news/340.html.

Davies, E. A., \& O'Mahony, M. S. (2015). Adverse drug reactions in special populations - older persons. British Journal of Clinical Pharmacology, 80(4), 796-807. https://doi.org/10.1111/bcp.12596

de Jong, M. R., Elst, M., \& Hartholt, K. (2013). Drug-related falls in older patients: Implicated drugs, consequences, and possible prevention strategies. Therapeutic Advance Drug Safety, 4(4), 147-54. https://doi.org/10.1177/2042098613486829

Elliott, R. A., \& Stehlik, P. (2013). Identifying inappropriate prescribing to older people. Journal of Pharmacy Practice Research, 43, 312-19. https://doi.org/10.1002/j.2055-2335.2013.tb00284.x

Eze, U. I. H., \& Olowo, A. O. (2011). Prescribing patterns and inappropriate use of medications in older outpatients in a tertiary hospital in Nigeria. Tropical Journal of Pharmaceutical Research, 10(1), 19-25. https://doi.org/10.4314/tjpr.v10i1.66536

Fadare, J. O., Agboola, S. M., Opeke, O. A., \& Alabi, R. A. (2013). Prescription pattern and prevalence of potentially inappropriate medications among older patients in a Nigerian rural tertiary hospital. Therapeutic Clinical Risk Management, 9, 115-20. https://doi.org/10.2147/tcrm.s40120

Federal Ministry of Health Nigeria (2008). Standard treatment guidelines.

Hamilton, H., Gallagher, P., Ryan, C., Byrne, S., \& O'Mahony, D. (2011). Potentially inappropriate medications defined by STOPP Criteria and the risk of adverse drug events in older hospitalised patients. Archives of internal medicine, 171(11), 1013-9. https://doi.org/10.1001/archinternmed.2011.215

Holt, S., Schmiedl, S., \& Thürmann, P. A. (2010). Potentially inappropriate medications in the elderly: the PRISCUS list. Deutsches Arzteblatt international, 107(31-32), 31-2. 
https://doi.org/10.3238/arztebl.2010.0543

Kondo, N., Nakamura, F., Yamazaki, S., Yamamoto, Y., Akizawa, T., Akiba, T. ... \& Fukuhara, S. (2015). Prescription of potentially inappropriate medications to elderly hemodialysis patients: Prevalence and predictors. Nephrology Dialysis Transplantation, 30, 498-505. https://doi.org/10.1093/ndt/gfu070

Maher, R. L., Hanlon, J., \& Hajjar, E. R. (2014). Clinical consequences of polypharmacy in elderly. Expert Opinion on Drug Safety, 13, 57-65. https://doi.org/10.1517/14740338.2013.827660

Narayan, S. W., \& Nishtala, P. S. (2015). Prevalence of potentially inappropriate medicine use in older New Zealanders: a population-level study using the updated 2012 Beers criteria. Journal of Evaluation in Clinical Practice, 21, 633-641. https://doi.org/10.1111/jep.12355

Novaes, P. H., da Cruz, D. T., Lucchetti, A. L. G., Leite, I. C. G., \& Lucchetti, G. (2017). The "iatrogenic triad": polypharmacy, drug-drug interactions, and potentially inappropriate medications in older adults. International Journal of Clinical Pharmacy, 39(4), 818-25. https://doi.org/10.1007/s11096-017-0470-2

Obreli-Neto, P. R., Nobili, A., de Oliveira Baldoni, A., Guidoni, C. M., de Lyra Júnior, D. P., Pilger, D., ... \& Cuman, R. K. (2012). Adverse drug reactions caused by drug-drug interactions in older outpatients: A prospective cohort study. European Journal of Clinical Pharmacology, 68(12), 1667-76. https://doi.org/10.1007/s00228-012-1309-3

O'Mahony, D., O'Sullivan, D., Byrne, S., O'Connor, M. N., Ryan, C., \& Gallagher, P. (2015). STOPP/START criteria for potentially inappropriate prescribing in older people: Version 2. Age Ageing, 44, $213-8$. https://doi.org/10.1093/ageing/afu145

Page, R. L., Linnebur, S. A., Bryant, L. L., \& Ruscin, J. M. (2010). Inappropriate prescribing in the hospitalized elderly patient: defining the problem, evaluation tools, and possible solutions. Clinical Intervention in Aging, 5, 75-87. https://doi.org/10.2147/cia.s9564

Park, K., \& Bavry, A. A. (2014). Risk of stroke associated with nonsteroidal anti-inflammatory drugs. Vascular Health Risk Management, 10, 25-32. https://doi.org/10.2147/vhrm.s54159

Patel, R., Zhu, L., Shohal, D., Lenkova, E., Koshki, N., Woelfel, J., .. \& Rogan, E. L. (2018). Use of 2015 Beers criteria medications by older medicine beneficiaries. Consultant Pharmacy, 33(1), 48-54. https://doi.org/10.4140/tcp.n.2018.48

Pradhan, S., Panda, A., Mohanty, M., Behera, J. P., Ramani, Y. R., \& Pradhan, P. K. (2015). A study of the prevalence of potentially inappropriate medication in elderly in a tertiary care teaching hospital in the state of Odisha. International Journal of Medicine and Public Health, 5, 344-348. https://doi.org/10.4103/2230-8598.165108

Rakesh, K. B., Chowta, M. N., Shenoy, A. K., Shastry, R., \& Pai, S. B. (2017). Evaluation of polypharmacy and appropriateness of prescription in geriatric patients: A cross-sectional study at a tertiary care hospital. Indian Journal of Pharmacology, 49(1).

Renom-Guiteras, A., Meyer, G., \& Thurmann, P. A. (2015). The EU (7)-PIM list: a list of potentially inappropriate medications for older people consented by experts from seven European countries. European Journal of Clinical Pharmacology, 71(7), 861-875. https://doi.org/10.1007/s00228-015-1860-9

Salwe, K. J., Kalyansundaram, D., \& Bahurupi, Y. A. (2016). Study on Polypharmacy and Potential Drug-Drug Interactions among older Patients Admitted in Department of Medicine of a Tertiary Care Hospital in Puducherry. Journal of Clinical Diagnostic Research, 10(2), 06-10. https://doi.org/10.7860/jcdr/2016/16284.7273

Shoshi A, Hoppe T, Kormeier B, Ogultarhan V, Hofestädt R. GraphSAW: A web-based system for graphical analysis of drug interactions and side effects using pharmaceutical and molecular data. BMC Medical Information Decision Making, 15, 15. https://doi.org/10.1186/s12911-015-0139-5

Ubeda, A., Ferrándiz, L., Maicas, N., Gomez, C., Bonet, M., \& Peris, J. E. (2012). Potentially inappropriate prescribing in institutionalized older patients in Spain: the STOPP-START criteria compared with the Beers criteria. Pharmacy Practice, 10(2), 83-91. https://doi.org/10.4321/s1886-36552012000200004

van der Stelt, C. A. K., Vermeulen Windsant-van den Tweel, A. M. A., Egberts, A. C. G., van den Bemt, P. M., Leendertse, A. J., Hermens, W. A., ... \& Derijks, H. J. (2016). The Association Between Potentially Inappropriate Prescribing and Medication-Related Hospital Admissions in Older Patients: A Nested Case Control Study. Drug Safety, 39(1), 79-87. https://doi.org/10.1007/s40264-015-0361-1 
van Heerden, J. A., Burger, J. R., \& Gerber, J. J. (2016). Inappropriate medicine prescribing in older South Africans: A cross-sectional analysis of medicine claims data. South African Medical Journal, 106(10), 1010-6. https://doi.org/10.7196/samj.2016.v106i10.10627

Woolcott, J. C., Richardson, K. J., Wiens, M. O., Patel, B., Marin, J., Khan, K. M., \& Marra, C. A. (2009). Meta-analysis of the impact of 9 medication classes on falls in older persons. Archives of Internal Medicine, 169(21), 1952-60. https://doi.org/10.1001/archinternmed.2009.357

World Health Organization [WHO]. (2002). Innovative care for chronic conditions: building blocks for action. World Health Organization.http://www.who.int/chp/knowledge/publications/icccglobalreport.pdf.

World Health Organization Centre for Health Development. (2004). A glossary of terms for community health care and services for older persons. World Health Organization, editor. WHO/WKC/Tech.Ser./04.2. 2004. Geneva, Switzerland. Ageing and Health Technical Report.

\section{Appendixes}

Appendix 1. The individual PIM among the study participants

\begin{tabular}{|c|c|c|}
\hline PIM & Frequency & Percentage \\
\hline Amitriptyline & 28 & 8.0 \\
\hline Amitriptyline, Bromazepam & 1 & 0.3 \\
\hline Amitriptyline, Glibenclamide, Trihexyphenidyl & 1 & 0.3 \\
\hline Amitriptyline, Prochlorperazine & 2 & 0.6 \\
\hline Amitriptyline, Dextropropoxyphene & 1 & 0.3 \\
\hline Amitriptyline, Diclofenac & 1 & 0.3 \\
\hline Amitriptyline, Trihexyphenidyl & 1 & 0.3 \\
\hline Aspirin & 1 & 0.3 \\
\hline Bromazepam & 5 & 1.4 \\
\hline Chlorpheniramine & 4 & 1.1 \\
\hline Chlorpromazine & 1 & 0.3 \\
\hline Chlorpromazine, Amitriptyline & 1 & 0.3 \\
\hline Dextropropoxyphene & 4 & 1.1 \\
\hline Diclofenac & 24 & 6.8 \\
\hline Diclofenac, Piroxicam & 1 & 0.3 \\
\hline Digoxin & 3 & 0.9 \\
\hline Dipyridamole & 2 & 0.6 \\
\hline Ephedrine & 1 & 0.3 \\
\hline Glibenclamide & 1 & 0.3 \\
\hline Glibenclamide, Diclofenac & 1 & 0.3 \\
\hline Ibuprofen & 1 & 0.3 \\
\hline Imipramine & 1 & 0.3 \\
\hline Methyldopa & 12 & 3.4 \\
\hline Methyldopa, Amitriptyline & 1 & 0.3 \\
\hline Metoclopramide & 1 & 0.3 \\
\hline Olanzapine, Amitriptyline & 2 & 0.6 \\
\hline Orphenadrine & 3 & 0.9 \\
\hline Phenobarbitone & 2 & 0.6 \\
\hline
\end{tabular}




\begin{tabular}{lll}
\hline Prazosin & 1 & 0.3 \\
Prochlorperazine & 3 & 0.9 \\
Prochlorperazine, Chlorpromazine & 1 & 0.3 \\
Risperidone & 1 & 0.3 \\
Risperidone, Orphenadrine, Amitriptyline & 1 & 0.3 \\
Trihexyphenidyl & 9 & 2.6 \\
Trihexyphenidyl, ibuprofen & 1 & 0.3 \\
Total & 124 & 100.0 \\
\hline
\end{tabular}

Appendix 2. The PIP according to the Beers drug-drug interactions list

\begin{tabular}{llll}
\hline Class of interacting drugs & Medicines involved & Frequency & Percentage \\
\hline 2 anticholinergic drugs & Amitriptyline + Prochlorperazine & 2 & 10.0 \\
& Amitriptyline+ Chlorpromazine & 1 & 5.0 \\
& Amitriptyline+ Olanzapine & 2 & 10.0 \\
& Amitriptyline+ Trihexyphenidyl & 2 & 10.0 \\
& Prochlorperazine+ Chlorpromazine & 1 & 5.0 \\
3 Central Nervous System active drugs & Resperidone+Amitriptyline+ Orphenadrine & 1 & 5.0 \\
Angiotensin converting enzymes inhibitors & Lisinopril+ Amiloride & 8 & 40.0 \\
Corticosteroid+ NSAIDs & Prednisolone+ Diclofenac & 2 & 10.0 \\
Alpha blocker+loop diuretic & Prasozin+Furosemide & 1 & 5.0 \\
\hline
\end{tabular}

\section{Copyrights}

Copyright for this article is retained by the author(s), with first publication rights granted to the journal.

This is an open-access article distributed under the terms and conditions of the Creative Commons Attribution license (http://creativecommons.org/licenses/by/4.0/). 